\title{
The Comparative Analysis of Gender and Social Network among Malay SMEs Entrepreneurs in Malaysia
}

\author{
Ehsan Fansuree Surin, Nurul Hafez Abd. Halil, and Oswald Timothy Edward
}

\begin{abstract}
The purpose of this paper is to make comparison in terms of social network between male and female Malay entrepreneurs in Small and Medium Enterprises (SMEs) in Malaysia. Social network is defined as interrelationship between the entrepreneurs and their contact (alter) in business venturing. However, there is limited understanding on how the entrepreneurs use their social network. Moreover, there is dearth attention given to investigate the social network in developing country especially in Malaysia. Both social network theory and structural perspective were employed in this quantitative-based study. The data gathered through the mail questionnaire method in which 93 are male and 72 female respondents representing 53 percent responded. Using t-test, the study reveals that there is no significance difference in terms of network size, network activity and network density for both genders. Implications and direction for further research are also presented.
\end{abstract}

Index Terms - Gender, Malay, SMEs, social network.

\section{INTRODUCTION}

A social network is defined as interrelationship between the entrepreneurs and their contact (alter/s) in business venturing [1]. The conception focus on the actor who connected to entrepreneur and a bulk of researches has analysed the social network between the entrepreneurs and their alter(s). The actors in social network comprise of family members, friends, relatives and business associates [2] [3]. With the aim to survive in the business, the social network is considered as a weapon to secure important resources for SME firms [4].

Over the past three decades, most of the scholars have given much attention in exploring the cause and effect of the social network [5]-[10]. However, little attention given to make a comparison the utilisation of social network between the gender [11]. Moreover, there has been little serious research carried out on social network theme in Malaysia especially Malay ethnic [12], [13]. Therefore, this paper endeavors to report the research findings on the adoption of social network properties; network size, network activity and network density between men and women Malay

Manuscript received October 16, 2013; revised January 19, 2014. This work was supported by Research Management Institute, Universiti Teknologi MARA under grant 600-RMI/DANA5/3/RIF (101/2012).

Ehsan Fansuree Surin is with the Faculty of Business Management, Universiti Teknologi MARA, 40000 Shah Alam, Selangor, Malaysia (e-mail efansuree@salam.uitm.edu.my).

Nurul Hafez Abd. Halil is with the Malaysian Academy of SME and Entrepreneurship Development (MASMED), Universiti Teknologi MARA, 40000 Shah Alam, Selangor, Malaysia (e-mail: hafez@salam.uitm.edu.my).

Oswald Timothy Edward is with the Universiti Teknologi MARA, 85000 Segamat, Johor, Malaysia (e-mail: oswald@johor.uitm.edu.my). entrepreneurs in SME firms in Malaysia. The research tries to answer the question of: Do Malay male and female entrepreneurs have significant difference in terms of network size, network activity and network density?

In addressing the above question, we make the following contributions. First, little attention given to study the social network in Malaysia, therefore this study shed light on the structural perspectives to spark the attention in understanding the social network phenomenon. Second, entrepreneurship scholars have failed to notice on how the social network is used and give the benefit to the firm [14]. Therefore, we advance the research on the value of social network specifically on Malay entrepreneurs who struggle to survive in business in their mainland. Lastly, most of the social network-based research focuses on cause-and-effect of the network; however the current study employs the comparative study between male and female. We hope that the findings of this study will serve a benefit to the entrepreneurs especially for those who have an intention to start the business.

\section{LiterATURE REVIEW}

\section{A. Social Network Theory}

The social network theory was popularised in the middle of 1980s and sought to explain the capability of the network to help the entrepreneur in accessing the resources [2]. This theory, on the other hand, integrates the concept of relationships into the exchange equation. In social network research, the person who we investigate their network is called ego, meanwhile the person that connect with the ego is called alter.

Social network is also broadly accepted as a tool for securing resources from alters [15]. The social network is largely characterised as personal ties and connections that are built on trust [16]. Trust is essential to the social network as it sustains and cultivates the network. Members of the social network trust one another to abide by the terms of the network into which they voluntarily enter. This trust is based on repeated interactions, exchange of resources and shared expectations of behaviour which is strengthened by the accepted norms of the network.

This paper adopted the structuralist perspective to measure the social network. The perspective explains the configuration of network ties [17]. The perspectives included in this paper are network size, network activity and network density.

\section{B. Network Size}

With respect to the gender differences, reference [18] found that women have smaller network size compared to 
men. Reference [19] revealed similar results that showed the significant difference in terms of the number of the network size where female reported to use larger relatives than the men. Similarly, scholar also noted that women used a higher degree of relatives in their social network compared to men [20]. Therefore, the following hypothesis is proposed;

$\mathrm{H}_{1}$ There is a significant difference between men and women entrepreneurs for network size

\section{Network Activity}

Research has shown that men invest more time in network activity [18]. Similarly, reference [21] asserted the evidence that there is a significant difference for men and women in amount spent in developing and maintaining their contact in Ireland. A research on financing in Bulgaria found that women may be at a disadvantage in their social network due to the less degree of networking [22]. Similarly, women encountered discrimination in social network especially when dealing with men entrepreneurs in Pakistan [23]. Therefore, we introduced the hypothesis as:

$\mathrm{H}_{2}$ There is a significant difference between men and women entrepreneurs for network activity

\section{Network Density}

The comparative study on gender associated with network density remains less. However, reference [21] concludes that men have denser network compared to women. This views however against the discovery by others researchers that found women entrepreneurs' alters have formed the closely knit in their network [24]. Similarly, research found that women entrepreneurs' networks have higher degree in network density [25]. Another investigation however found that both genders depend on male contact to get an advice [21]. Further, family members made up the significant roles in the women network [19], and women tend to name their friends and family members as a primary contact [26]. Women tend to use the strong ties (friends and family members) because they did not have access to the professional bodies [7]. In addition, women confront with inadequacy of time to create a social network therefore avoid the close relationship with others [27]. Therefore, the hypothesis stated as:

$\mathrm{H}_{3}$ There is a significant difference between men and women entrepreneurs for network density

\section{RESEARCH METHOD}

\section{A. Sample and Setting}

Our unit of analysis is Malay entrepreneur. For the purpose of this paper, we define the entrepreneurs as the owner-manager that running their business for the profit. Those owner-managers will be SMEs that involve in manufacturing industry. Manufacturing industry is selected based on the following reasons; a) The SMEs in the manufacturing industry form a vital component of the Malaysian economy in terms of their numbers and contributions to the nation's economy [28], b) a research on network is likely to be more valid by using single-industry studies which the network emphasizes on strategic critical linkages [5].
The sample of manufacturing companies was compiled through the following sources; SME Corporation Malaysia, Federation of Malaysian Manufacturers (FFM) and Malaysia External Trade Development Corporation. The list was then analysed and a new list was compiled to only include manufacturing companies. The listing were then categorised the companies according to their geographical zones (North, South, East Coast and Central) and stratified random sampling was used to select the sample [29]. Five main sectors were chosen into the listing; food and beverage, wood-based product, rubber-based product, electric and electronics and textiles, apparel and leather represent 60 percent from the total number of SMEs in Malaysia. The data were collected through mailing surveys to the owner-managers listed in the sample directory. Overall, 165 $(53 \%)$ completed questionnaires were received within four months.

\section{B. Measurement of Variables}

The self-generated answer to indicate the number of the contact by the owner manager through the ego-network method and a simple count of network contact as an indicator of network size are consistent with prior research to examine the entrepreneurial network [18]. One month was given due to recall back purposes and the use of shorter time frame deems appropriate to avoid respondents' recall lacks validity.

In order to examine the network activity, entrepreneurs were required to answer a questionnaire regarding the frequency of interactions with their alters. The 5-point Likert-type scale: 1 (very seldom) to 5 (very often) was used to assess the frequency of interactions with the four categories of alters; family members, relatives, friends and business contact.

To measure the network density, the question asked the entrepreneurs to nominate five names of their alters they had been in contact with over the last month. Based on the name listed by entrepreneurs, they are then asked to rate how familiar each alter is with other members in the network through three items which are adopted and modified from [30]. The respondents were then asked to indicate on 5-point Likert-type scale: 1 (strongly disagreed) to 5 (strongly agreed).

\section{ANALYSES AND FINDINGS}

\section{A. Descriptive Analyses}

Table I reveals the respondents' and firms' profile. The respondents consist of male (93) and female (72). Regarding the age, majority of the respondents were above 45 years old (41.2\%), 41 to 45 (20\%), 36 to $40(18.8 \%), 31$ to 35 (12.7\%), whereas only 7.3 percent were 26 to 30 years of age. For marital status, more than half of the respondents were married $(86.7 \%), 12.1$ percent of the respondents were single and the remaining $(1.2 \%)$ were divorced.

For the respondents' business type, the sample consisted of sole-proprietorship (65), private-limited company (63) and for partnership-based company (37). The majority of the firms come from food and beverage sector (70.9\%), while wood-based product sector represents 21.8 percent, 
rubber-based product $(3 \%)$, electric and electronics $(2.4 \%)$ and textiles, apparel and leather sector represents (1.9\%). Most of the firms operated in Southern region (57), followed by Western Northern region (41), Northern region (36) and Eastern region (31).

TABLE I: THE RESPONDENTS’ AND FIRMS’ PROFILE

\begin{tabular}{|c|c|c|}
\hline Firms' Profile & Number & Percentage \\
\hline \multicolumn{3}{|l|}{ Gender } \\
\hline Male & 93 & 56.4 \\
\hline Female & 72 & 43.6 \\
\hline \multicolumn{3}{|l|}{ Respondents' Age } \\
\hline 25 or under & 0 & 0 \\
\hline $26-30$ & 12 & 7.3 \\
\hline $31-35$ & 21 & 12.7 \\
\hline $36-40$ & 31 & 18.8 \\
\hline $41-45$ & 33 & 20 \\
\hline 46 and above & 68 & 41.2 \\
\hline \multicolumn{3}{|l|}{ Marital status } \\
\hline Married & 143 & 86.7 \\
\hline Single & 20 & 12.1 \\
\hline Divorced & 2 & 1.2 \\
\hline \multicolumn{3}{|l|}{ Business type } \\
\hline Sole proprietorship & 65 & 39.4 \\
\hline Partnership & 63 & 38.2 \\
\hline Private limited & 37 & 22.4 \\
\hline \multicolumn{3}{|l|}{ Business sector } \\
\hline Food and beverage & 117 & 70.9 \\
\hline Wood-based product & 36 & 21.8 \\
\hline Rubber-based product & 5 & 3 \\
\hline Electric and electronics & 4 & 2.4 \\
\hline Textiles, apparel and leather & 3 & 1.9 \\
\hline \multicolumn{3}{|l|}{ States and (Region) } \\
\hline Perlis (northern) & 4 & 2.4 \\
\hline Kedah (northern) & 8 & 4.8 \\
\hline Pulau Pinang (northern) & 10 & 6 \\
\hline Perak (northern) & 14 & 8.4 \\
\hline Selangor (central) & 37 & 22.4 \\
\hline Kuala Lumpur (central) & 4 & 2.4 \\
\hline Negeri Sembilan (southern) & 11 & 6.8 \\
\hline Melaka (southern) & 11 & 6.8 \\
\hline Johor (southern) & 35 & 21.2 \\
\hline Pahang (east coast) & 16 & 9.7 \\
\hline Kelantan (east coast) & 8 & 4.9 \\
\hline Terengganu (east coast) & 7 & 4.2 \\
\hline
\end{tabular}

\section{B. Hypotheses Testing}

The t-test analysis is employed to measure the differences in network size (log), network activity and network density for men and women entrepreneurs. The distribution of the size of the network is skewed, therefore logarithm method is used to normalise the data since the parametric statistics requires the normal distribution among the sample [31]. Table II gives overall picture on t-test findings on three variables of social network on gender. Given the Levene's test for all the variables have a probability greater than .05, the assumption of population variances are considered equal. For network size (log), a significance value of 0.249 (greater than 0.05 ), indicates that there is no significant difference between the gender. Therefore, we concluded that there was no significant difference between male and female entrepreneurs in terms of network size and $\mathrm{H}_{1}$ is rejected.
TABLE II: THE RESULTS OF INDEPENDENTS GROUP T-TEST

\begin{tabular}{lccc}
\hline \hline Variables & $t$ & Sig. & Results \\
\hline Network size $(\log )$ & -1.157 & 0.249 & Not supported \\
Network activity & -1.361 & 0.176 & Not supported \\
Network density & -0.759 & 0.449 & Not supported \\
& & & \\
\hline \hline
\end{tabular}

The second hypothesis comprises of network activity showed that $\mathrm{p}$ value 0.176 is higher than 0.05 . Therefore, the second hypothesis is also rejected. The last hypothesis for network density, it can be seen that significance value of $p=$ 0.449 is greater than 0.05 , therefore we reject the $\mathrm{H}_{3}$. We conclude that there was no significant difference between men and women entrepreneurs in network density.

\section{DisCUSSION}

The findings of the current study provide the view that gender does not provide the significant difference in terms of the utilisation of the social network properties: network size, network activity and network density. The first finding indicates that men and women are not significantly different in terms of network size. Our finding supports the earlier finding. Previous research discovers that men and women entrepreneurs have almost similar in terms of average size of alters [21], [32]. Further, the findings with respect to network activity suggest there is no significant difference between the genders. This finding supports the view of reference [11], [21]. Their studies state that men and women have used the network at the same rate. Finally, the result indicates that men and women have no significant different regarding the network density, thereby again consistent with the view of previous investigations [21], [33]. Prior researcher has found both genders have embedded in their social network with high degrees of interconnectedness [34].

\section{CONCLUSION}

In conclusion, our study extends the exploration on social network-based research by comparing the utilisation of social network between men and women entrepreneurs. The survey data provides the conclusion that no significant difference between men and women entrepreneurs in terms of utilisation of social network. Business practitioners can be benefited from our study by carefully selecting and creating the legitimate social network in order to enhance the business performance especially for those interested to create a new business.

It seems prudent to delineate a couple of caveats in this study. First, we have failed to obtain a "truly representative" sample. Most of the sample was located in the southern region (Johor, Melaka and Negeri Sembilan) and central region (Selangor and Kuala Lumpur). Therefore, the findings cannot be generalised to the whole SMEs population across Malaysia. Further, the sectoral biases that are of concern in this study arise from the investigation concentrating SME manufacturing firms. The current study attempts to examine the social network for the following sectors; (1) food and beverages (2) wood-based product (3) rubber-based product (4) electric and electronics and (5) textiles, apparel and 
leather. Therefore, the results produced might differ from that of other sectors.

Perhaps future research could conduct studies across the various ethnic communities in Malaysia. It should also be analysed whether the heterogeneity of the communities imply changes in the relationship of the constructs. Another possibility is that future studies could examine on how industries differ in terms of their social network. The current study represents an analysis of the social network structure for manufacturing industries. The upcoming studies should be aimed to explore the social network for service industries. Attention should also be given to provide more comprehensive studies on the social network between the manufacturing and services industries.

\section{REFERENCES}

[1] C. J. Fombrun, "Strategies for network research in organizations," Academy of Management Review, vol. 7, no. 2, pp. 280-291, Apr. 1982.

[2] S. Birley, "The role of networks in the entrepreneurial process," Journal of Business Venturing, vol. 1, no. 1, pp. 107-117, 1985.

[3] S. P. Premaratne, "Networks, resources, and small business growth: The experience in Sri Lanka," Journal of Small Business Management, vol. 39, no. 4, pp. 363-371, Oct. 2001.

[4] M. C. D. Garcia and S. Cater, "Resource mobilization through business owner's network: Is gender an issue?" International Journal of Gender and Entrepreneurship, vol. 1, no. 3, pp. 226-252, 2009.

[5] H. Hoang and B. Antoncic, "Network-based research in entrepreneurship: A critical review," Journal of Business Venturing, vol. 18, no. 2, pp. 165-187, March 2003.

[6] X. Quan and Y. Motoyama, "Empirical disaggregation of social networks: A study of ethnic professional associations and entrepreneurship in Silicon Valley," Journal of Small Business and Entrepreneurship, vol. 23, no. 4, pp. 509-526, Dec. 2010.

[7] J. Watson, "Modeling the relationship between networking and firm performance." Journal of Business Venturing, vol. 22, no. 6, pp. 852-874, Nov. 2007.

[8] F. Sepulveda and M. Gabrielsson, "Network development and firm growth: A resource-based study of B2B Born Globals," Industrial Marketing Management, vol. 42, no. 5, pp. 792-804, July 2013.

[9] E. Nybakk, A. Lunnan, J. I. Jenssen, and P. Crespell, "The importance of social networks in the Norwegian firewood industry," Biomass and Bioenergy, vol. 57, pp. 48-56, Oct. 2013.

[10] J. Hu and J. Stanton, "A study of how mainland Chinese small and medium privately owned businesses engage in networking," Industrial Marketing Management, vol. 40, no. 4, pp. 534-539, May 2011.

[11] S. H. Fisher, "Female entrepreneurs making connections: Networking by women small business owners," Ph.D. dissertation, School of Business and Technology, Capella University, Minnesota, 2010.

[12] A. B. Hamed, "The personal networks of small firm entrepreneurs in Malaysia: An exploratory study," Unpublished Ph.D. thesis, Department of Management Studies, University of Glasgow, 1995.

[13] A. G. Farinda, Y. Kamarulzaman, A. Abdullah, and S. Z. Ahmad, "Building business networking: A proposed framework for Malaysian SMEs," International Review of Business Research Papers, vol. 5, pp. 2, pp. 151-160, 2009.

[14] T. L. Amburgey and H. Rao, "Organizational ecology: Past, present, and future directions," Academy of Management Journal, vol. 39, no. 5, pp. 1265-1286, Oct. 1996.

[15] K. V. Laere and A. Heena, "Social networks as a source of competitive advantage for the firm," Journal of Workplace Learning, vol. 15, no. 6 , pp. 248-258, 2003.

[16] S. T. Porras, S. Clegg, and J. Crawford, "Trust as networking knowledge: Precedents from Australia," Asia Pacific Journal of Management, vol. 21, no. 3, pp. 345-363, 2004.

[17] S. P. Borgatti and P. C. Foster, "The network paradigm in organizational research: A review and typology," Journal of Management, vol. 29, no. 6, pp. 991-1013, 2003.

[18] P. R. Reese, "Entrepreneurial networks and resource acquisition: Does gender make a difference?" Ph.D. dissertation, Department of Sociology, The University of North Carolina, 1992.

[19] A. Greve and J. W. Salaff, "Social networks and entrepreneurship," Entrepreneurship: Theory and Practice, vol. 28, no. 1, pp. 1-22, Dec. 2003.
[20] D. P. Moore, "An examination of present research on the female entrepreneur - Suggested research strategies for the 1990s," Journal of Business Ethics, vol. 9, no. 4-5, pp. 275-281, May 1990.

[21] S. Cromie and S. Birley, "Networking by female business owners in Northern Ireland," Journal of Business Venturing, vol. 7, no. 3, pp. 237-251, May 1992.

[22] T. S. Manolova, I. M. Manev, N. M. Carter, and B. S. Gyoshev, "Breaking the family and friends' circle: Predictors of external financing usage among men and women entrepreneurs in a transitional economy," Venture Capital, vol. 8, no. 2, pp. 109-132, April 2006.

[23] M. H. Qureshi, S. Ayyub, M. Ramzan, Q. Zaman, and M. Yasir, "Factors affecting small-business performance in Punjab-Pakistan: A gender based analysis," Interdisciplinary Journal of Contemporary, vol. 4, no. 2, June 2012.

[24] C. L. Ridgeway and L. S. Lovin, "The gender system and interaction," Annual Review of Sociology, vol. 25, pp. 191-216, Aug. 1999.

[25] L. A. Renzulli and H. Aldrich, "Who can you turn to tie activation within core business discussion networks," Social Forces, vol. 84, no. 1, pp. 323-341, Sept. 2005.

[26] S. Robinson and H. A. Stubberud, "Sources of advice in entrepreneurship: Gender differences in business owners' social networks," International Journal of Entrepreneurship, vol. 13, pp. 83-101, 2009.

[27] L. Martin, "Are women better at organisational learning an SME perspective," Women in Management Review, vol. 16, no. 6, pp. 287-296, 2001.

[28] C. S. Long and W. K. W. Ismail, "The vital roles of human resource professional: A study on the manufacturing companies in Malaysia," The Journal of International Management Studies, vol. 3, no. 2, pp. 114-125, Aug. 2008.

[29] N. Ismail and M. Jantan, "Unraveling the links between dimensions of technology strategy and the performance of Malaysian SMEs: Exploring the moderating effect of the dynamic environment," Journal of International Business and Entrepreneurship, vol. 10, no. 2, pp. 71-96, 2004.

[30] B. J. Frazier, "The influence of network characteristics on information access, marketing competence and perceptions of performance in small rural businesses," Ph.D dissertation, Department of Human Environment, Michigan State University, 2000.

[31] S. J. Coakes and L. G. Steed, SPSS. Analysis without Anguish: Version 11.0 for Windows, John Wiley and Sons, Australia, 2007.

[32] L. A. Renzulli, H. Aldrich, and J. Moody, "Family matters: Gender, networks, and entrepreneurial outcomes," Social Forces, vol. 79, no. 2, pp. 523-546, Dec. 2000.

[33] H. Aldrich, "Networking among women entrepreneurs," in Women-Owned Businesses, O. Hagan, C. Rivchun, and D. Sexton, Eds., New York: Praeger, 1989, pp. 103-132.

[34] K. Klyver and S. A. Terjesen, "Entrepreneurial network composition: An analysis across venture development stage and gender," Women in Management Review, vol. 22, no. 8, pp. 682-688, 2007.

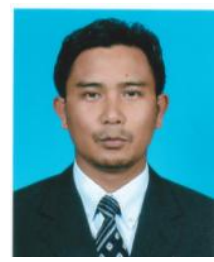

Ehsan Fansuree Surin is a lecturer at Universiti Teknologi Mara, Shah Alam, Selangor, Malaysia. He obtained his MBA (finance) and first degree (operation management) from Universiti Teknologi Mara, Malaysia in 2005 and 2003. Prior to this, he worked as a lecturer at International University College of Twintech in Bandar Sri Damansara, Selangor, Malaysia. His current research focused on small business social network and strategic planning.

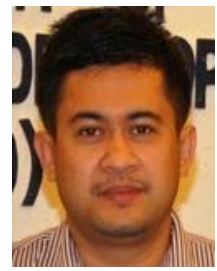

Nurul Hafez Abd. Halil is a lecturer at Malaysian Academy of SME and Entrepreneurship Development (MASMED), Universiti Teknologi Mara, Shah Alam, Selangor, Malaysia. He obtained his MSc (Information Technology) from Universiti Teknologi Mara, Malaysia in 2004. Prior to the current career, he worked as consultant, business development, marketing namely. His current research focused on entrepreneurship and innovation (concept, context and commercialisation).

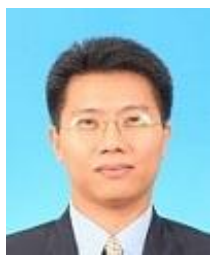

Oswald Timothy Edward is a senior lecturer at Universiti Teknologi Mara, Segamat, Johor, Malaysia. He obtained his MBA from Universiti Putra Malaysia in 2002. Prior to the current position, he worked as an insurance brokers with Sime Darby, kuala Lumpur. His research interests include the entrepreneurial orientation and culture. 